\title{
Dysphagia Management and Stroke Units
}

\author{
David G. Smithard ${ }^{1,2}$
}

Published online: 23 November 2016

(C) The Author(s) 2016. This article is published with open access at Springerlink.com

\begin{abstract}
Dysphagia is one of the many complications of stroke. It is common and is an independent marker of outcome. Dysphagia management is important. Although the speech and language pathologist is the key worker in dysphagia management, they are supported by all members of the multi-disciplinary team. Stroke patients should be screened on admission for the presence of dysphagia and assessed by the speech and language therapist (or appropriate professional), where indicated investigation should be undertaken to understand the swallowing physiology and to guide treatment. Management, at present, is based around texture modification of food/liquids and swallowing manoeuvres. Rehabilitation of swallowing remains in its infancy, but there is a lot of promising research with neurostimulation, medication and devices to strengthen muscles involved in swallowing.
\end{abstract}

Keywords Dysphagia · Swallow · Swallowing disorders · Stroke $\cdot$ Stroke units $\cdot$ Review

\section{Introduction}

Dysphagia is a common problem after stroke, with a reported prevalence up to $60 \%$, which may rise to $100 \%$ if minor deficits such as minor tongue weakness are accepted as

This article is part of the Topical Collection on Swallowing Disorders

David G. Smithard

david.smithard@nhs.net

1 Department of Electronics and Digital Arts, University of Kent, Canterbury, UK

2 Princess Royal University Hospital, King's College Hospital, London, UK evidence of dysphagia. In many cases, dysphagia resolves fairly quickly, but in others, the swallow will vary in function $[1,2]$.

The act of swallowing is complex, not only peripherally but also centrally. Swallowing is essentially a reflex, which follows a set pattern initiated in the brainstem. The swallow is a synchronous and continuous event, once triggered. The events occur in a set order, but the duration of laryngeal elevation, UES opening and breath holding will vary depending on the bolus characteristics (volume and viscosity). Stroke affects swallowing at multiple levels due to the interruption of the feedback loop, with recovery depending on the cortical recovery [3].

With an ageing society, the incidence/prevalence of dysphagia is increasing. Many older people will have presbyphagia, and depending on their frailty, the prevalence of dysphagia may be as high as $70 \%$; consequently, not all dysphagia on a stroke unit will be of a stroke origin. Work by Smithard et al. [1] found that there were people, who, 1 week after their stroke, had dysphagia which had not been noted at the time of their initial admission assessment. Swallowing after stroke is variable [1, 4]; therefore, constant awareness and review need to be undertaken to ensure that where problems exist, they are detected.

The identification and management of dysphagia are important to minimise the risk of infection (usually because of poor mouth care) $[5,6]$, distress due to aspiration of food and liquids and the ability to provide adequate calories.

\section{Stroke Units}

Stroke management is multiprofessional and interprofessional not only in its entirety of the pathway but also sections of the pathway such as the management of swallowing problems. 
Good practice dictates that people admitted to hospital with an acute stroke should be managed on a stroke unit.

Stroke units are clinical areas dedicated to the care of people admitted to hospital with stroke. Stroke units are staffed by professionals with an interest in and knowledge of stroke. Evidence has shown that people cared for on stroke units recover better and are less likely to die both in the short and long terms (odds of death $0.82 ; 95 \% \mathrm{CI}$, 0.77 to 0.87 ; P0.00001) $[7,8]$.

It is not completely clear which elements of a stroke unit deliver the improved outcome. It is probably the overall ethos, coordinated care by expert staff, increased awareness engendered of stroke complications and care by such a unit, as well as the ability to be entered into clinical trials and to see a specialist [9-14].

Stroke team members should be conversant with dysphagia, how to identify it and what the management is, to position (sitting up between $45^{\circ}$ and $90^{\circ}$, be alert and able to follow instructions), screen, assess and manage people with dysphagia. The inability to follow instructions does not mean that the assessment cannot be conducted; it does mean, however, that a novel or pragmatic approach may be required.

The clinical management of dysphagia will be complicated by the presence of hemianopia, sensory neglect, cognition and personal dislikes.

\section{Dysphagia Management}

Dysphagia is defined as "difficulty in swallowing; the transfer of food from the mouth to the stomach", whereas eating difficulties refer to the problems associated with the transfer of food/ liquid to the mouth. For many patients, the problems coexist.

The management of dysphagia is similar in most stroke services across the world, but is shaped by the availability of resources and the staff to undertake the service.

Many services are able to offer swallow screening at the time of admission or within $24 \mathrm{~h}$ by following a protocol. $[15,16]$. There is much variability in the management plan, but managing stroke in a predetermined manner improves outcome $[15,17$, 18]. The swallowing pathway has several key components to it. These are described in more details in various guideline documents [19] and a consensus statement by the ESSD [20•].

The generally accepted pathway consists of screening, assessment, investigation, management, rehabilitation and feeding (Fig. 1).

\section{Screening}

There needs to be a consensus as to the purpose and meaning of screening. Within the acute stroke setting, it is generally

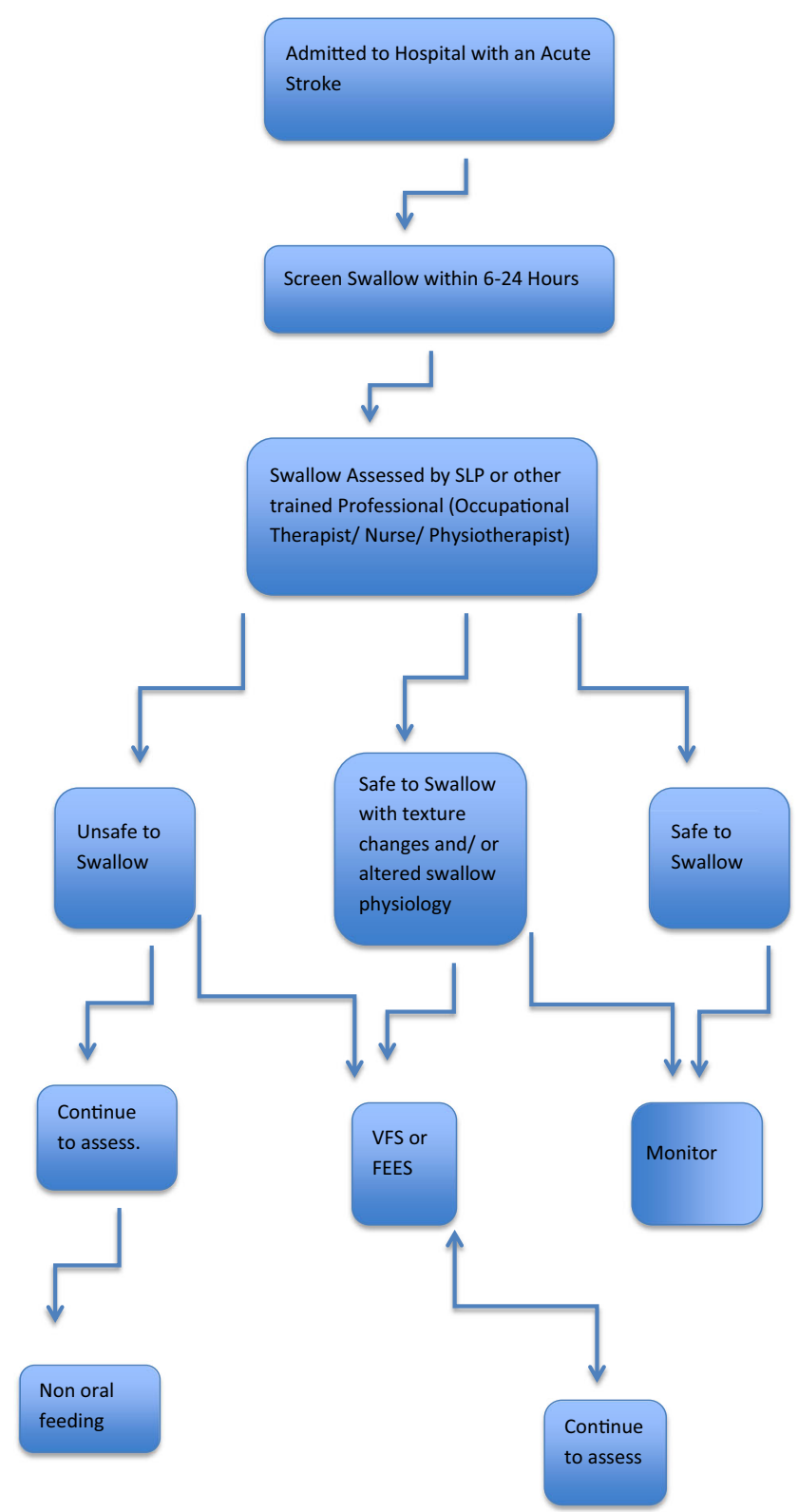

Fig. 1 Swallow screening of patients admitted to hospital with an acute stroke

taken to mean an assessment undertaken early, using one consistency (water) [21, 22]. Some screening tools, such as The Mann Assessment of Swallowing Ability (MASA) and miniMASA [23] rely on clinically generated variable to determine the presence of dysphagia and risk of aspiration. The screening of stroke patients for the presence of dysphagia is undertaken to identify those who can or cannot swallow safely. The swallow screen is not a diagnostic tool. Most swallow screens are based around the bedside swallowing assessment [1] and use varying volumes of water to assess the ability to swallow [1, 22, 23]. The swallow screen does not provide the ability to make swallowing management decisions beyond able to swallow/not able to swallow safely. 
The question is which swallow screen and who undertakes it. There are many swallow screens available [24] therefore the need to develop, yet another similar screen is unwarranted. Who undertakes the screen will depend on the stroke service designed. In the UK, nurses from the stroke service will undertake the screen, usually on the ward; in the USA, Daniels reported on success of emergency department training nurses to undertake the screen $[16,25,26]$.

The sensitivities and specificities of swallow screens are varied (Fig. 2) and in attempts to improve the sensitivity of the water swallow screen, research had been undertaken on the additional benefit of cervical auscultation, arterial oxygen saturation and the addition of contrast media to the water supplemented with a chest radiograph [27]. Bours et al. [28] have suggested that oxygen saturation with the water swallow test is the best approach, yet the literature remains mixed [27]. Ramsey et al. [27] undertook a randomised study to investigate the added benefit of a chest radiograph to the bedside screen. Unfortunately, due to a mix of factors, recruitment of the appropriate patients was not possible [27].

A swallow screen needs to be sensitive to detect those with swallowing problems/aspiration and to those who have a normal swallow (specificity) (Fig. 2). These correlate reasonably well. The correlation between sensitivity and specificity and positive and negative predictive values, however, is generally poor (unpublished data). Kopey et al. [29] found that the sensitivity was poor but specificity was high in those with stroke that passed the test; $54.6 \%$ had clinically significant dysphagia. Their conclusion was that a high suspicion of dysphagia should remain in those with more dependent stroke (FIM <60). The swallow screen needs to be used easily and produce the same outcome independent on the operator [1,26].

In Bristol, UK, a report at the European stroke conference suggested that the use of the miniMASA reduces the occurrence of aspiration pneumonia on the stroke unit by $75 \%$ (12 to 3\%) [30]; however, recent reports suggest that now the study has finished, practice has returned to prestudy ways and chest infection rates are back at pre-study levels (personal communication).

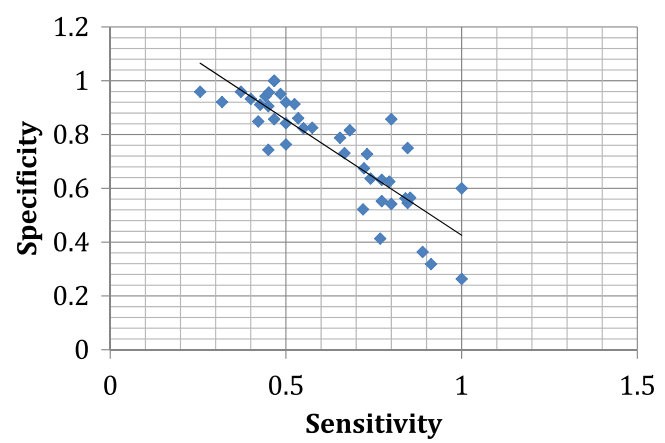

Fig. 2 Relationship between specificity and sensitivity of swallow screens. Unpublished data (DG Smithard)
Whichever screen is used and by whom may not be relevant, Hinchey et al. noted that the presence of a protocol in a service improved outcomes and reduced aspiration pneumonia $[15,31,32]$.

The 2015 SSNAP [33] audit in the UK reported that nationally, $71 \%$ of swallows were assessed with a screen within $4 \mathrm{~h}$ of admission and $83.6 \%$ had an assessment by an SLT within 72 h. In Germany, figures were lower (2008) but screening occurred on $55.8-86.6 \%$ depending on the unit [34]. Titsworth et al. [35] found that using nursing staff to deliver a swallow screen followed by speech and language Pathologist (SLP) where indicated improved compliance with screening (39.3 to $72.4 \% p<0.001)$ and consequent reduction in pneumonia.

\section{Swallow Assessment}

Assessment is the next stage of management and involved a more detailed examination of the swallow, by someone trained in swallowing assessment $[16,36]$. The assessment will review the oral anatomy, sitting balance and neurology of the patient as well as the swallow following stroke.

The swallowing assessment is conducted by those specifically trained to undertake it. The actual professional will vary by country $[16,20 \bullet, 36-42]$. Whatever local situations dictate, the assessment should be early and undertaken by a trained specialist.

The swallow will be assessed using different consistencies of food/liquid (texture-modified food) and using different techniques to assist the swallow where indicated.

Following the swallowing assessment advice will be provided regarding the provision of food; this will range from normal diet, modified diet, speed of feeding, volume of each mouthful, need for supervision whilst eating/swallowing and the need for swallowing manoeuvres (e.g. head position, forceful swallow) or where the swallow is very unsafe, nil by mouth.

There is no standardised assessment [41], but the recent development of the V-VST [43] may provide a basis for a consistent approach.

A swallow assessed as safe may not remain safe during the length of someone's stay in the stroke unit. The swallow may deteriorate with intercurrent events such as infection, uncontrolled diabetes, head injury following fall or recurrent stroke. Medication prescribed by the medical team may affect the swallow or result in confusion due to anticholinergic effects $[44,45]$.

\section{Investigation}

Further investigation of the swallow may be required following clinical assessment. Any instrumental assessment needs to add value to the patient's care; there are essentially two treatment 
methods, one radiological and the other endoscopic; they are complementary techniques [28, 46, 47].

The purpose of further assessment is to determine what is happening during the swallow. Videofluoroscopy (VFS) or modified barium swallow is often accepted as a "gold standard" for assessing the swallow. This is based on the fact that it was the first assessment developed. VFS provides data on bolus flow, muscle movement and the relationship of anatomy with the aspiration [2, 46]. However, it does entail the person being taken to radiology and a brief barium study and being exposed to $\mathrm{x}$-rays. If someone is unable to sit in a special chair, the assessment may not be possible.

Fibreoptic endoscopic evaluation of swallowing (FEES) can be conducted at the bedside and can, therefore, be conducted in people who may be too unwell or who have poor sitting balance [48]. It does not expose people to radiology but requires a trained operator, and aspiration may be missed. FEES is not readily available in all units [16], though it is possible to train many different professionals in its use $[49,50]$.

Internationally, there are differences of opinion as to the clinical appropriateness of instrumental investigation; should all people undergo VFs or FEES or only where there is a clinical need to answer a specific question pertaining to management. [11-14]. Wilson in his MSc thesis [51] suggests that assessment followed by VF is the most cost-effective management structure; it is possible that VFS may delay the commencement of oral feeding and certainly, follow-up studies may not always show a physiological change despite a functional change.

\section{Rehabilitation}

Rehabilitation and management of dysphagia are often confused. Many of the mechanisms used to assist people to swallow safely are thought of as rehabilitation techniques.

\section{Swallow Management}

The provision of nutrients is important and fundamental; the management of dysphagia is to ensure the safe provision of adequate nutrition; failure to provide adequate nutrition will ultimately result in the death of the patient.

Presently, there are three approaches to managing a poor swallow: to alter the physiology of the swallow (manoeuvres) or to alter the consistency of the diet or a combination of both (Table 1). Research has shown that the use of texture modification and swallowing manoeuvres is beneficial in reducing aspiration and hopefully any consequences. However, there is a risk that the consistency of fluid thickening and food textures may not be consistent. Prepared foods/liquids are expensive.
Table 1 Swallowing manoeuvres to assist in a reducing aspiration and producing a safe swallow

Forceful swallow

Double swallow

Breath holding

Supraglottic swallow

Suprsupra glottic swallow

Mendelssohn manoeuvre

Head turn

Chin tuck

Position of bolus in the mouth

There are two groups working on the production of guidelines to assist $[52 \bullet, 53 \bullet]$.

All staff working on the stroke unit, the visitor (family/friend), volunteer, housekeeper, nurse, therapist and medical staff, need to be aware of any advice or instruction given by the SLP which should be visible and followed.

The SLP works in conjunction with the physiotherapist to assist with sitting and positioning, the occupational therapist to assist in special cutlery and plates/plate guards and the dietician to ensure adequate calories are being provided.

The greatest issue for patients and staff alike is the limited opportunity to undertake rehabilitation as opposed to the provision of assessment and advice. This is a result of a high workload and too few numbers of trained personnel. Despite the time constraints, dysphagia squeezes out dysphasia management in the acute and early post acute setting.

\section{Rehabilitation}

Dysphagia rehabilitation as opposed to dysphagia management is gathering increasing momentum, with many researchers taking an interest and an increasing evidence base. The end outcome for any rehabilitation intervention is for someone to be able to swallow safely. Whichever technique is used, neuroplasticity will occur due to swallowing being a rich feedback system [54].

Physical rehabilitation of the swallow at present relies on the strengthening of hyoid musculature. This has taken several approaches, with variable effect. Tongue strengthening exercises [55-57] have been shown to benefit and improve swallowing safety after stroke. Exercises that work directly on the hyoid musculature for example the Shaker Manoeuvre [58] and more recently chin tuck against resistance (CTAR) [59•] also improve swallowing. Vitalstim [60] and Ampcare [61] both work via neuromuscular stimulation but more evidence is needed before either technique is accepted into everyday practice.

Scutt et al. [62] have been investigating the role of pharyngeal stimulation. A nasogastric tube, with electrodes and 
sensors, is passed to enable feeding and provide therapy by stimulating the pharynx at set thresholds and frequency for defined time periods. At present, further work is required to determine exactly who would benefit.

Transcranial magnetic stimulation has provided a great insight as to the recovery of swallowing, but as yet is not a rehabilitative technique available in the clinical setting.

\section{Nutrition and Hydration}

As many as $24 \%$ of people admitted with an acute stroke are at risk of being malnourished [63]. More patients may become malnourished during admission due to many factors including illness, neglect, hemiparesis and hemianopia. Many people will require feeding and may not be supported $[64,65]$.

\section{Route}

Many questions persist regarding the provision of food/nutrition as opposed to water. In the immediate $24-48 \mathrm{~h}$ of stroke, patients will need to be hydrated. Most guidelines suggest that an intravenous infusion of saline should be provided.

The optimal route for the provision of nutrition and hydration is orally or enterally. This keeps the gut functioning and reduces metabolic upset. If oral feeding cannot be provided, an alternative route can be considered. However, it has become recognised that those on a texture-modified diet have a reduced energy and protein intake and greater deficit to their requirements than those on a normal diet [66]; a similar situation is present for thickened fluids [67-69].

More contentious is the timing of the placement of a nasogastric tube. There are risks associated with nasogastric tube (NGT) placement including the placement of the tube within the bronchus of the right lung. Keeping NGTs in place can be difficult. NGTs frequently "fall out". The reasons for this are multiple, from poor fixation to the patient pulling it out.

The use of NGT as a method of feeding is accepted. There has been scepticism as to the risk versus benefit of a nasogastric tube. An argument has been that the NGT may increase the risk of infection/aspiration, or cause physical damage to the pharynx, oesophagus or lung. NGTs can be misplaced and lead to feed passing into the lung if not spotted. Dzeiwas in 2003 [70] found that dysphagia was not exacerbated by the use of NGT and more recently Kalra et al. [71] have shown, in a larger study, that the use of NGT did not increase the occurrence of infection or mortality.

A small study by Davlos et al. [72] concluded that early enteral feeding did not prevent a negative protein balance. The FOOD [73] trial concluded that early feeding did reduce mortality by $5.8 \%$ but at the expense of increased disability in those that survived. Crary et al. [74] have not found a link between nutrition and dysphagia in the acute phase of stroke; the link with hydration is more complex as the more severe stroke patients will often be provided with intravenous hydration.

Consensus is that a nasogastric tube should be placed early to allow the administration of medication.

Following the FOOD trial [73], early placement of a percutaneous endoscopic gastrostomy tube was not recommended and could be delayed by several weeks, but this will be dictated as to whether the NGT remains in situ. Various devices have been used to maintain the NGT in place from tape, through the nasal bridle, to an American football helmet.

Appropriate identification of people requiring percutaneous endoscopic gastrostomy (PEG) feeding reduces the placement of tubes into people where it is not warranted, either because their care is palliative or that the swallow is improving.

Stroke units need to have policies and standard operating procedures in place, as to the timing of the provision of enteral nutrition. There are frequent delays between the decision to place the feeding tube to its placement and subsequent implementation. The placement of a PEG may vary due to the availability of services. Ideally, the PEG should be inserted within $72 \mathrm{~h}$ after the decision for insertion/placement has been made [14].

It is important not to procrastinate and excessively delay the provision of nutrition, as rehabilitation will be delayed, recovery is adversely affected.

Parenteral feeding should rarely be indicated following an acute stroke. In the majority of people, the gastrointestinal tract is functioning and therefore, enteral nutrition should be the route of choice. Where it is difficult to maintain NGT feeding or difficult to pass an NGT for anatomical reasons, parenteral nutrition is a useful interim route for nutrition, whilst waiting the placement of a PEG.

\section{Infection}

The aspiration of food is potentially lethal, due to mechanical obstruction and pneumonitis $[75,76]$ rather than infection. The aspiration of saliva, on the other hand, carries a greater significant risk. The surface area of the teeth and gums is large [77, 78] and for every cubic centimetre, there are billion organisms. Mouth care is therefore vital but frequently neglected. Neglect is particularly a problem where non-oral feeding is being used, yet is relatively straight forward. Studies by Gosney et al. [79] and Rofes et al. [80] have shown that the use of simple mouth care with the addition of oral decontamination with metronidazole gel or mouthwash and toothpaste will reduce the incidence of infection [79, 80]. Latterly, Roffe's group has shown that the use of metoclopramide may reduce the occurrence of aspiration [81]. 
The presence of hemiparesis and a reduction in chest wall movement on the hemiparetic side led to the theory that the lack of ventilation and sputum stasis may result in infection; however, two large randomised studies have shown that the use of prophylactic antibiotics did not reduce the occurrence of pneumonia in patients with dysphagia $[82,83]$.

\section{Future}

Stroke will remain a burden on people, health services and society for many years. The incidence, if not prevalence, will increase as the population ages. Its management needs to be improved with rehabilitation occurring outside of hospitals. Research is required to develop devices that are simple, straightforward and at the same time effective. These devices need to be portable and to be able to be used by the patient alone or when being advised at a distance using telehealth.

Medication may aid those with an impaired rather than an absent swallow. Clavé's group has been undertaking some interesting work with TRPV1 [83] receptor agonists; other works have suggested that Nifedipine, amantadine and substance P may offer some benefit $[84,85]$.

\section{Ethical Issues}

Every stroke unit needs to be mindful that just because something can be done, it does not mean that it should be. Internationally, restraints are used to maintain the position of the NGT. In the UK, simple restraints are used regularly in an attempt to stop NGTs being removed. The use of mittens, physical restraints or chemical restraints raises not only legal but ethical issues.

People should not be compelled to undertake a course of action that may be unwarranted or unwanted. Both approaches could be perceived as assault, morally unacceptable and ethically undefendable if the treatment does not have any demonstrable likely benefit.

Stroke units need to have in place a protocol/policy, to manage dysphagia in patients where tube feeding is not warranted or not wanted. This will need to be developed in conjunction with end of life care.

\section{Conclusions}

The management of dysphagia on stroke units is the concern of all who work there. Stroke units should have policies to direct the care and reduce the occurrence of pneumonia and other complications associated with aspiration.

The swallow should be promptly assessed and where indicated further investigations should be organised.
The institution of nutrition and hydration is of prime importance and needs to be implemented promptly.

\section{Compliance with Ethical Standards}

Conflict of Interest David G. Smithard has received fees as speaker for Nestle and received fees as chair for Nutricia.

Human and Animal Rights and Informed Consent This article does not contain any studies with human or animal subjects performed by any of the authors.

Open Access This article is distributed under the terms of the Creative Commons Attribution 4.0 International License (http:// creativecommons.org/licenses/by/4.0/), which permits unrestricted use, distribution, and reproduction in any medium, provided you give appropriate credit to the original author(s) and the source, provide a link to the Creative Commons license, and indicate if changes were made.

\section{References}

Papers of particular interest, published recently, have been highlighted as:

- Of importance

1. Smithard DG, O’Neil PA, England RE, Park CL, Wyatt R, Martin DF, Morris J. The natural history of dysphagia following stroke. Dysphagia. 1997;12:188-93.

2. Heckert KD, Konnaroff E, Adler U, Barrett AM. Post acute reevaluation may prevent dysphagia-associated morbidity. Stroke 2009;40:1381-1385.

3. Hamdy S, Rothwell JC, Aziz Q, Singh KD, Thompson DG. Longterm reorganization of human cerebral motor cortex driven by short-term sensory stimulation. Nat Neurosci 1988;1:64-68

4. Mann G, Hankey GJ, Cameron D. Swallowing function after stroke. Stroke. 1999;30:744-8.

5. Ueda K, Yamada Y, Toyosato A, Nomura S, Saitho E. Effects of functional training of dysphagia to prevent pneumonia for patients on tube feeding. Gerontology. 2004;21:108-11.

6. Langdon PC, Lee AH, Binns CW. High incidence of respiratory infections in nil by mouth tube-fed acute ischemic stroke patients. Neuroepidemiology 2009;32:107-113.

7. Seenan P, Long M, Langhorne P. Stroke units in the natural habitat. Stroke 2007;38:1886-1892.

8. Zhu HF, Newcommon NN, Cooper ME, Green TL Seal B, Klein G, Weir NU et al. Impact of a stroke unit on length of hospital stay and in-hospital case fatality. Stroke 2009;40:18-23.

9. Stroke unit trialists collaboration. Collaborative systematic review of the randomised trials of organised inpatient (stroke unit) care after stroke. BMJ 1997;314:1151-1159

10. Langhorne P, Bernhardt J, Kwakel G. Stroke rehabilitation. Lancet. 2011;377:1693-702.

11. New Zealand Clinical Guidelines for Stroke Management 2010. Stroke Foundation New Zealand.

12. Clinical Guidelines for Stroke Management 2010. National Stroke Foundation www.strokefoundation.co.au.

13. European Stroke Organisation Writing Committee. Guidelines for management of ischaemic stroke and transient ischaemic attack 2008. Cerebrovasc Dis. 2008;25:457-507. 
14. Wirth R, Smoliner C, Jager M, Warnecke T, Leischker AH, Dziewas R, and the DEGM steering committee. Guideline clinical nutrition in patients with stroke. Exp Transl Stroke Med. 2013;5:14.

15. Hinchey JA, Shephard T, Furie K, Smith D, Wang D, Tonn S. Formal dysphagia screening protocols prevent pneumonia. Stroke. 2005;36:1972-6.

16. Fairfield C, Smithard, D. Management of sysphagia in the acute phase: a consideration of international practice. Dysphagia across ages. 4th Congress of European Society of Swallowing Disorders. Congress Abstracts. Dysphagia 2015;30: 213-271.

17. Oddderson R, Keaton JC, McKenna BS. Swallow management in patients on an acute stroke pathway: quality is cost effective. Arch Phys Med Rehabil. 1995;76:1130-3.

18. Gandolfi M, Smania N, Bisoffi G, Squaquara T, Zuccher P, Mazzucco S. Improving post-stroke dysphagia outcomes through a standardized and multidisciplinary protocol: an exploratory cohort study. Dysphagia. 2014;29:704-12.

19. SIGN Guideline 119: Management of patients with stroke: identification and management of dysphagia.

20. ESSDPosition statement: screening, diagnosis and treatment of oropharyngeal dysphagia in stroke patients. Dysphagia 2013;28:280-

335 . This statement attempts to define what should be the way to manage patients with dysphagia following stroke, whilst acknowledging the differences in practice across Europe.

21. Trapl M, Enderle P, Nowontony M, Teuschl Y, Matz K, Dachenhausen A, Brainin M. Dysphagia bedside screening for acute stroke patients. Stroke. 2007;38:2948-52.

22. Martino R., Silver F, Teasell R, Bayley M, Nicholson MG, Streiner DL, Diamant N. The Toronto bedside swallowing assessment screening (TOR-BSST) Stroke 2009;40:555-561.

23. Antonois N, Carnaby-Mann G, Crary M, Miller L, Hubbard H, Hood K, Sambandam R, Xavier A, Silliman S. Analysis of a physician tool for evaluating dysphagia on an inpatient stroke unit: the modified Mann assessment of swallowing ability. J Stroke Cerbrovasc Dis. 2010;19(1):48-57.

24. Speyer R. Oropharyngeal dysphagia. Otolaryngol Clin N Am 2013;46:989-1008

25. Edmiaston J, Connor LT, Loehr L, Nassief A. Validation of a dysphagia screening tool in acute stroke patients. Am J Crit Care. 2010;19:357-64.

26. Daniels SK, Anderson JA, Petersen NJ. Implementation of stroke dysphagia screening in the emergency department. Nursing Res and Practice Volume. 2013;2013:304190. 7 pages. Accessed July 2016

27. Ramsey DJC, Smithard DG, Kalra L. Early assessment of dysphagia and aspiration risk in acute stroke patients. Stroke. 2003;34: 1252-7.

28. Bours GJJW, Limburg M, Speyer R. Bedside screening tests vs videofluroscopy or fibreoptic endoscopic evaluation of swallowing to detect dysphagia in patients with neurological disorders: systematic review. J Advanced Nursing 2009.

29. Kopey JA, Chae J, Vargo M. Does a 3-sip test detect dysphagia in acute stroke rehabilitation patients? Phys Med and Rehabil. 2010;2: $822-8$.

30. Mohr NI, Baldwin N, White P. Analysis of the implementation of a validated swallowing screening tool for acute stroke: the Modified Mann Assessment of Swallowing Ability (MMASA). Int J Stroke. 2011;6(S2):8.

31. Yeh SH, Huang KY, Wang TG, Chen YC, Chen CH, Tang SC, Tsai LK, Yip PK, Jeng JS. Dysphagia screening decreases pneumonia in acute stroke patients admitted to a stroke intensive care unit. J Neurol Sci. 2011;306:38-41.

32. Middleton S, McElduff P, Ward J, Grimshaw JM, Dale S, D'Este C, Drury P, Griffiths R, Cheung NW, Quinn C, Evans M, Cadilhac D, Levi C. Implementation of evidence-based treatment protocols to manage fever, hyperglycaemia, and swallow dysfunction in acute stroke (QASC): a cluster randomised trial. Lancet. Published online October 2011;12.

33. SSNAP www.strokeaudit.org.

34. Wiedemann S, Hillman S, Abilleira S, Dennis M, Hermanek P, Niewada M, Norvig B, Asplund K, Rudd AG, Wolfe CDA, Heuschmann PU. Variations in hospital care and factors influencing quality indicators in 6 European audits. Stroke. 2015;46:579-81.

35. Titsworth WL, Abram J, Fullerton A, Hester J, Guin P, Waters MF, Mocco J. Prospective quality initiative to maximize dysphagia screening reduces hospital-acquired pneumonia prevalence in patients with stroke. Stroke. 2013;44:3154-60.

36. Regan J, Walshe M, McMahon BP. Current evaluation of upper oesophageal sphincter opening in dysphagia practice: an international SLT survey. Int J Commun Disord. 2102;47:156-165.

37. Kamal RM, Ward E, Cornwell P. Dysphagia management practices among speech-language pathologists in Malaysia. Asia Pac J Speech, Lang Hear. 2012;15:111-8.

38. Mathers-Schmidt BA, Kurlinski M. Dysphagia evaluation practices: inconsistencies in clinical practice and instrumental examination. Dysphagia. 2003;18:114-25.

39. Ramsey D, Smithard D, Donaldson N, Kalra L. Is the gag reflex useful in the management of swallowing problems in acute stroke? Dysphagia. 2005;20:105-7.

40. Bateman C, Lelsie P, Drinnan MJ. Adult dysphagia assessment in the UK and Ireland: are SLTs assessing the same factors? Dysphagia. 2007;22:174-86.

41. Martino R, Pron G, Daimonte N. Screening for oropharyngeal dysphagia in stroke: insufficient evidence for guidelines. Dysphagia. 2001;15:19-30.

42. Leder SB, Suiter DM, Warner HL, Acton LM, Swainson BA. Success of recommending oral diets in acute stroke patients based on passing a 90-cc water swallow challenge protocol. Top Stroke Rehabil 2012;19:40-44.

43. Rofes L, Arreola V, Mukherjee R, Calve P. Sensitivity and specificity of the eating assessment tool and the volume-viscosity swallow test for clinical evaluation of oro-pharyngeal dysphagia. Neurogastroenterol Motil. 2014;26:1256-65.

44. Fox C, Richardson K, Maidment ID, Savva GM, Matthews FE, Smithard D, Coulton S, Katona C, Boustani MA, Brayne C. Anticholinergic medication use and cognitive impairment in the older population: the Medical Research Council cognitive function and ageing study. JAGS. 2011;59:1477-83.

45. Lindroos E, Saarela RKT, Soini H, Muurinen S, Suominen MH, Pitkala KH. Caregiver reported swallowing difficulties, malnutrition and mortality among older people in assisted living facilities. $\mathrm{J}$ Nutr Health Aging. 2014;18:718-22.

46. Palmer JB, Kuhlemeier KV, Tippett DC, Lynch C. A protocol for the videofluorographic study. Dysphagia. 1993;8:209-14.

47. Pikus L, Levine MS, Yang YX, Rubesin SE, Katzka DA, Laufer I, Gefter WB. Videofluoroscopic studies of swallowing dysfunction and the relative risk of pneumonia. AJR. 2003;180:1613-6.

48. Warnacke T, Teismann I, Oclenberg S, Hamacher C, Ringelstein EB, Schabitz WR, Dziewas R. The safety of fibreoptic endoscopic evaluation of swallowing in acute stroke patients. Stroke. 2009;40: $482-6$.

49. Dziewas R, Warnecke T, Hamacher C, Oelenberg S, Teismann I, Kraemer C, et al. Do nasogastric tubes worsen dysphagia in patients with acute stroke? BMC Neurol. 2008;8:28.

50. Dziewas R, Glahn J, Helfer C, Ickstein G, Keller J, Ledl C, LindnerPfleghar B, Nabavia DG, Prosiegel M, Riecker A, Lapa S, Stanchis $\mathrm{S}$, Warnecke T, Busse O. Flexible endoscopic evaluation of swallowing (FEES) for neurogenic dysphagia: training curriculum of the German Society of Neurology and the German Stroke Society. BMC Med Educ. 2016;16:70.

51. Wilson RD. A cost effectiveness analysis of methods of screening for dysphagia after stroke. MSc Thesis Case Western Univ 2009. 
52. Newman R, Vilardell N, Calve P, Speyer R. Effect of bolus viscosity on the safety and efficacy of swallowing and the kinematics of the swallow response in patients with oropharyngeal dysphagia: white paper by the European Society for Swallowing Disorders (ESSD). Dysphagia. 2016;31:232-49. This paper present the evidence that the chaneg of bolus consistency has on the relative movements of the pharynx, bolus and the safety of swallowing. It is an attempt to understand the affect of texture/viscosity modification and to bring standardisation to a clinical technique.

53. Steele CM, Alsanei WA, Ayanikalath S, Barbon CEA, Chen J, Cichero JAY, et al. The influence of food texture and liquid consistency modification on swallowing physiology and function: a systematic review. Dysphagia. 2015;(30):2-26. Modified diets, particularly fluids and thickeners, have suffered with a lack of consistency in approach and delivery. These two papers have begun the process to develop harmonisation and reliability in approach to the provision of modified fluids and solids.

54. Barritt AW, Smithard DG. Role of cerebral cortex plasticity in the recovery of swallowing function following dysphagic stroke. Dysphagia. 2009;24:83-90.

55. Butler SG, Stuart A, Leng X, Wilhelm E, Rees C, Williamson J, Kritchevsky SB. The relationship of aspiration status with tongue and handgrip strength in healthy older adults. J Gerontol A Biol Sci Med Sci. 2011;1-7

56. Robbins JA, Kays SA, Gangon RE, Hind JA, Hewitt AL, Gentry LR, Taylor AJ. The effects of lingual exercise in stroke patients with dysphagia. Arch Phys Med Rehabil. 2007;88:150-8.

57. Steele CM, Bailey CM, Polacco REC, Hori SF, Molfenter SM, Oshalla M, Yeates EM. Outcomes of tongue-pressure strength and accuracy training for dysphagia following acquired brain injury. Int J Speech-Lang Pathol. 2013;15:492-502.

58. Shaker R, Easterling C, Kern M, Nitschke T, Massey B, Daniels S, Grande B, Kazandijian M, Dikeman K. Rehabilitation of swallowing exercise in tube-fed patients with pharyngeal dysphagia secondary to abnormal UES opening. Gastroenertol. 2002;122: 1314-21.

59. Yoon WL, Khoo JKP, Liow SJR. Chin tuck against resistance (CTAR): new method for enhancing suprahyoid muscle activity using a Shaker exercise. Dysphagia. 2014;29:243-8. This paper highlighted an alternative approach to the delivery of hyoid muscle exercise that is possible for most people to utilise, resulting in further research for many people and bringing hope. It is an approach that is easily applied clinically and does not require expensive equipment or specific training.

60. Li L, Yin J, Shen Y, Qiao B, Li Y, Shi J. The value of adding transcutaneous neuromuscular electricall stimulation (VitalStim) to traditional therapy for post stroke dysphagia: a randomised controlled study. Rev Ecuat Neurol 2012;21:1-3

61. Pownall S, Spronson L, Enderby P, Freeman, J.R. Randomized controlled trial of the Ampcare Effective Swallowing Protocol for persistent dysphagia after stroke. http://www.swallowtherapy. com/wp-content/uploads/2015/01/ESSD-V.5.-Phase-II-Researchdarker-font.pdf.

62. Scutt P, Lee HS, Hamdy S, Bath PM. Pharyngeal electrical stimulation for treatment of post stroke dysphagia: individual patient data meta-analysis of randomised controlled trials. Stroke Res Treat. 2015; doi:10.1155/2015/429053.

63. Axelsson K, Asplund K, Norberg A, Alafuzoff I. Nutritional status in patients with acute stroke. Acta Medica Scandanavia. 1988;224(3):217-24.

64. Poels BJJ, Brinkman-Zijker HG, Dijkstra PU, Postma K. Malnutrition, eating difficulties and feeding dependence in a stroke rehabilitation centre. Disabil Rehabil. 2006;28:637-43.

65. Martineau J, Bauer JD, Isenning E, Cohen S. Malnutrition determined by the patient-generated subjective global assessment is associated with poor outcomes in acute stroke patients. Clin Nutr. 2005;24:1073-7.

66. Wright L, Cotter D, Hickson M, Frost G. Comparison of energy and protein intakes of older people consuming a texture modified diet with a normal hospital diet. J Hum Nutr Dietet. 2005;18:213-9.

67. Karagiannis MJP, Chivers JP, Karagiannis TC. Effects of oral intake of water in patients with oropharyngeal dysphagia. BMC Geriatrics. 2011;11:9. http://www.biomedcentral.com/1471-2318/11/9.

68. Cichero JAY. Thickening agents used for dysphagia management: effect on bioavailability of medication and feelings of satiety. Nutr J. 2013;12:54. http://www.nutritionj.com/content/12/1/54.

69. Whelan K. Inadequate fluid intakes in dysphagic acute stroke. Clin Nutr. 2001;20:423-8.

70. Dziewas R, Schilling M, Konrad C, Stogbauer F, Ludemann P. Placing nasogastric tubes in stroke patients with dysphagia: efficiency and tolerability of the reflex placement. JNNP. 2003;74: 1429-31.

71. Kalra L, Hodsoll J, Irshad J, Smithard D, Manawadu D. Association between nasogastric tubes, pneumonia and clinical outcomes in acute stroke patients. JNNP 2016 on line.

72. Davalos A, Ricart W, Gonzalez-Huix F, Soler S, Marrugat J, Molins A, Suner R, Genfs D. Effect of malnutrition after acute stroke on clinical outcome. Stroke. 1996;27:1028-7.

73. Food trialists collaboration. Effect of timing and method of enteral tube feeding for dysphagic stroke patients (FOOD): a multicentre randomised controlled trial. Lancet. 2005;365:764-72.

74. Crary MA, Humphrey J, Carnaby-Mann G, Sambandam R, Miller L, Silliman S. Dysphagia, nutrition, and hydration in ischaemic stroke patients at admission and discharge from acute care. Dysphagia. 2013;28:69-76.

75. Sura L, Madhavan A, Carnaby G, Crary MA. Dysphagia in the elderly: management and nutritional considerations Clin Interventions in Aging 2012;7:287-298

76. Finlayson O, Kapral M, Hall R, Asllani E, Selchen D, Saposnik G. Risk factors, inpatient care and outcomes of pneumonia after ischaemic stroke. Neurology. 2011;77:1338-45.

77. Ximéne-Fyvie LA, Haffajee AD, Scoransky SS. Comparison of the microbiota of supra- and subgingival plaque in health and periodontitis. J Clin Periodontol. 2000;27:648-57.

78. Seedat J, Penn C. Implementing oral care to reduce aspiration pneumonia amongst patients with dysphagia in a South African setting. South African J Communication Disorders. 2016;63(1) Art. \#102 doi:10.4102/sajcd.v63i1.102.11 pages.

79. Gosney M, Martin MV, Wright AE. The role of selective decontamination of the digestive tract in acute stroke. Age Ageing. 2006;33:42-7.

80. Rofes L, Arreola V, Martin A, Calve P. Natural capsicinoids improve swallow response in older patients with oropharyngeal dysphagia. Gut. 2013;62:1280-7.

81. Warunsevitane A, Karunatilake D, Sim J, Lally F, Roffe C. Safety and effect of metoclopramide to prevent pneumonia in patients with stroke fed via nasogastric tube. Stroke. 2015;46:454-60.

82. Kalra L, Irshad S, Hodsoll J, Simpson M, Gulliford M, Smithard D, Patel A, Rebello-Mesa I. Prophylactic antibiotics after acute stroke for reducing pneumonia in patients with dysphagia (STROKE-INF): a prospective, cluster-randomised, open-label, masked endpoint, controlled clinical trial. Lancet. 2015;386:1835-44.

83. Westendorp WF, Vermeij J-D, Zock E, Hooijenga I, Kruyt ND, Bosboom HJL, et al. The preventive antibiotics in stroke study (PASS): a pragmatic randomised open-label masked endpoint clinical trial. Lancet. 2015; doi:10.1016/S0140-6736(14)62456-9.

84. Perez I, Smithard DG, Davies H, Kalra L. Pharmacological treatment of dysphagia in stroke. Dysphagia. 1998;13:12-6.

85. Smithard DG. Substance P and swallowing after stroke. Future Med. 2006;3:291-8. 